\title{
Casos Clínicos \\ Temblor y mioclonías generalizadas
provocadas por antimoniato de meglumina
}

Tremor and generalized mioclonus caused by meglumine antimoniate

\author{
Luis Torres-Ramirez ${ }^{1}$, Melissa Pérez-Almedo ${ }^{2}$, Miriam Vélez-Rojas ${ }^{1}$, \\ Martha Flores-Mendoza ${ }^{1}$, Victor Arias-Hancco ${ }^{3}$
}

Resumen

La Leishmaniasis cutánea es una patología endémica en Perú, el tratamiento de primera línea son los antimoniales pentavalentes. Los antimoniales ocasionan como efecto secundario, síntomas neurológicos que pueden llegar a ser incapacitantes, por lo que debemos ser estrictos en la dosificación al momento de administrarlos. Presentamos el caso de un paciente varón de 56 años, que luego de tratamiento con antimoniato de Meglumina (Glucantime ${ }^{\circledR}$ ), presenta temblor, dismetría, ataxia y mioclonías generalizadas que le impiden la marcha.

Palabras clave: Antimoniales pentavalentes, ataxia, mioclonía generalizada, temblor.

\section{Abstract}

Cutaneous Leishmaniasis is an endemic pathology in Peru, the first line treatment being pentavalent antimonials. Occasional antimonials as the side effect, neurological symptoms that can become incapacitating, so we must be strict in the dosage at the time of administration. We present the case of a 56-year-old male patient, who treated with Meglumina Antimoniate (Glucantime $\left.{ }^{\circledR}\right)$, presented tremor, dysmetria, ataxia and generalized myoclonus that prevented him from walking

Keywords: Ataxia, generalized myoclonus, pentavalent antimonials, tremor.

\section{Introducción}

La leishmaniasis cutánea es endémica en más de setenta países del mundo, principalmente en trópicos, regiones subtropicales y cuenca mediterránea. Perú es uno de los diez países con el mayor número de casos, así como Afganistán, Argelia, Brasil, Colombia, Costa Rica, Etiopía, Irán, Sudán del Norte y Siria; juntos representan el $75 \%$ de la incidencia mundial $^{(1)}$. Los antimoniales pentavalentes son los fármacos de elección para el tratamiento de Leishmaniasis, a pesar de sus limitaciones, efectos secundarios y la necesidad de administración parenteral diaria. Estudios recientes sugieren que el Antimonio pentavalente actúa como un profármaco que se convierte en antimonio trivalente activo y más tóxico ${ }^{(2)}$. En el caso del N-methyl-glucamine antimonate - antimoniato de meglumina (Glucantime ${ }^{\mathbb{}}$ ), los efectos adversos clínicos más frecuentes son mialgias, artralgias, náuseas, vómitos, diarrea, dolor abdominal, cefalea, anorexia, astenia, fiebre, exantema y urticaria. Solo en un 7\% se reportan trastornos neurológicos, entre ellos la ataxia ${ }^{(3,4)}$, no se ha descrito mioclonías generalizadas como efecto adverso.
Presentamos el caso de un paciente con temblor y mioclonías en todas las extremidades y ataxia después de haber recibido antimoniales pentavalentes como tratamiento para Leishmaniasis cutánea.

\section{Caso clínico}

Paciente de 56 años de edad, masculino, procedente de Oxapampa - Departamento de Pasco, con primaria incompleta, soltero, vive en zona rural y se dedica a la agricultura. La familia refiere que en la infancia tuvo un bajo rendimiento académico en los primeros años de escolaridad por un posible retardo mental; sin embargo, vive solo, se autofinancia y es independiente para las actividades de la vida cotidiana. A los veinte años de edad padeció de "uta" cutánea y recibió tratamiento que no recuerda el paciente ni los familiares. Tiene hipertensión arterial desde hace tres años con tratamiento irregular. Fue hospitalizado en abril 2018 en un centro médico de su localidad, debido a que varios meses atrás presentaba úlcera cutánea en miembro inferior izquierdo, no dolorosa, que

${ }^{\prime}$ Médico Neurólogo del Instituto Nacional de Ciencias Neurológicas. ${ }^{2}$ Médico Residente de Neurología Universidad Nacional de San Agustín-Arequipa. ${ }^{3}$ Médico Residente de Neurología Universidad Nacional Federico Villarreal. 
no mejoraban ni desaparecían con el tiempo, le diagnosticaron Leishmaniasis cutánea. Recibió tratamiento con antimoniato de Meglumina (Glucantime ${ }^{\mathbb{R}}$ ), tres ampollas de $5 \mathrm{ml}$ por día durante 17 días por vía intramuscular. Presentó una evolución clínica favorable, por lo que fue dado de alta. Una semana después del término del tratamiento, presenta temblor leve en miembro superior derecho (MSD), los siguientes días el temblor compromete miembro superior izquierdo (MII) y se exacerba en intensidad y frecuencia. Se agrega inestabilidad en la marcha, camina con dificultad, con pasos cortos y torpes. Después de tres semanas el temblor persiste y se añaden movimientos involuntarios generalizados, como "sacudidas" que le impiden caminar solo, volviéndose dependiente para la mayoría de actividades diarias, por lo cual es traído por emergencia. En el examen neurológico se encuentra lenguaje poco comprensible por disartria severa, entiende y obedece órdenes simples, pupilas y movimientos oculares conservados, nistagmo horizontal. Temblor postural que se exacerba con la acción, presente en las cuatro extremidades a predominio de MSD, temblor mandibular, no rigidez ni bradicinesia, mioclonías generalizadas que se incrementan con la estimulación táctil y al intentar ponerse de pie. No tiene déficit motor ni sensitivo, puede ponerse de pie con dificultad por inestabilidad y requiere apoyo, amplía la base de sustentación, no puede iniciar la marcha debido a las mioclonías. Dismetría y adiadococinesia bilateral a predominio de MSD; hiperreflexia osteotendinosa, signo de Babinski derecho y clonus bilateral. En la pierna izquierda, se evidencia una lesión cutánea redondeada de $3 \mathrm{~cm}$ de diámetro de bordes elevados levemente eritematosa, correspondiente a una úlcera en resolución. No se encontró hepato ni esplenomegalia.

Los estudios de laboratorio realizados: Hemograma, creatinina, urea, glucosa, perfil hepático, perfil tiroideo y dosaje de Vitamina B12, todos con resultados normales. Se solicitó ELISA VIH, RPR y Anticuerpo antinuclear (ANA), que fueron negativos. El Eletroencefalograma prolongado $\mathrm{y}$ Electrocardiograma informados como normales. La Resonancia Magnética Nuclear Cerebral, mostró múltiples imágenes de hiperseñal puntiformes y confluentes en sustancia blanca del lóbulo frontal, parietal bilateral y temporal izquierdo; lesiones no captadoras de contraste (Figura 1).

Se decide iniciar tratamiento con pulsos de corticoide, Metilprednisolona 1g por día por 5 días, luego se administra Deflazacort como mantenimiento por la sospecha de Leuco encefalopatía de etiología a determinar. A pesar del tratamiento no presentó mejoría de los síntomas, después de una semana presentó trastornos de la conducta, negativismo, angustia, agitación e ideas paranoides, concluyéndose que se trataba de una psicosis probablemente secundaria a corticoides. Se disminuyó la dosis en forma progresiva y los síntomas psiquiátricos mejoraron. Posteriormente tiene una evolución lenta, con disminución progresiva del temblor, ataxia y mioclonías, al salir de alta, aún presentaba dismetría bilateral, se mantenía en pie y caminaba ampliando la base de sustentación ya podía realizar sus actividades básicas como comer y asearse. Recibió clonazepam 2 mgs/día.

\section{Discusión}

La leishmaniasis está constituida por un grupo de enfermedades causadas por varias especies de protozoos del

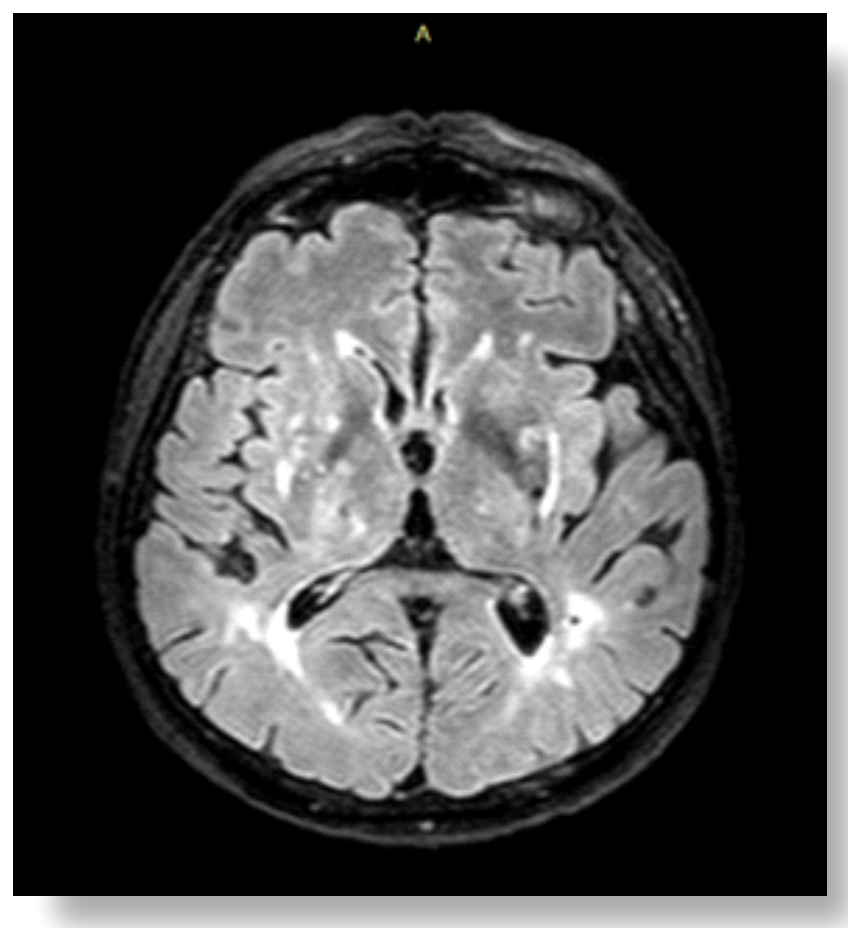

Figura 1. La Resonancia Magnética Nuclear Cerebral, mostró múltiples imágenes de hiperseñal puntiformes y confluentes en sustancia blanca del lóbulo frontal, parietal bilateral y temporal izquierdo; lesiones no captadoras de contraste.

género Leishmania, que son transmitidos a los humanos por dípteros flebotominos hembra (Phlebotomus y Lutzomyia). Se estima que 12 millones de pacientes sufren de leishmaniasis, con 0.7 a 1.2 millones de nuevos casos por año en todo el mundo, principalmente en personas que viven en áreas endémicas [1]. Puede presentarse en 3 formas clínicas: cutánea, cutáneo-mucosa y visceral; la mayoría de infecciones son asintomáticas y el período de incubación va de una semana a varios meses $^{(5)}$.

La forma cutánea (Leishmaniasis cutánea andina, también conocida como UTA en Perú), la lesión comienza como una pequeña zona de eritema en el lugar de la picadura que evoluciona a pápula y aumenta de tamaño ${ }^{(6)}$. Posteriormente, puede ulcerarse en el centro y presentar un borde sobre elevado, bien definido e hiperpigmentado. Las úlceras pueden ser secas o exudativas. La mayoría de las veces se ven afectadas las zonas expuestas, no hay clínica sistémica ni dolor local. Las lesiones suelen curar espontáneamente en 6 a 12 meses y dejan cicatriz. La complicación más frecuente es la sobreinfección bacteriana ${ }^{(7)}$. La leishmaniasis cutánea es una patología endémica de nuestro país, sobre todo en provincias de la sierra y selva, una de ellas es Oxapampa, el lugar de procedencia de nuestro paciente. El aumento en el número de pacientes inmuno suprimidos, debido a infección por VIH, post-trasplante, quimioterapia y terapias biológicas recientemente introducidas para afecciones inflamatorias crónicas, han resultado en una multiplicación de los casos de leishmaniasis ${ }^{(8)}$.

Los dos antimoniales principales, bajo uso clínico actual, son complejos de Antimonio (Sb) con N-metil-D- 
glucamina (antimoniato de meglumina o Glucantime ${ }^{\circledR}$ ) y gluconato sódico (estibogluconato sódico o Pentostam ${ }^{\circledR}$ ). Aunque la estructura exacta de estos complejos permaneció desconocida durante décadas, principalmente debido al estado amorfo de estos compuestos, el uso de enfoques de espectrometría de masas y técnicas de Resonancia Magnética Nuclear por protones ha permitido un progreso significativo en esta área ${ }^{(2)}$.

En nuestro país el Glucantime ${ }^{\circledR}$ es el medicamento de elección y los detalles de su administración en las diferentes presentaciones clínicas de Leishmaniasis están establecidos en la Guía Clínica del Ministerio de Salud. Su presentación es en forma de ampollas de $5 \mathrm{ml}$ que contiene $1.5 \mathrm{~g}$ de antimonial (como sal) que es equivalente a $425 \mathrm{mg}$ de Antimonio puro. $\mathrm{La}$ dosis que debe administrarse en caso de Leishmaniasis cutánea es de $20 \mathrm{mg} / \mathrm{kg} /$ día por 10-20 días ${ }^{(3)}$.

La asociación entre ataxia y tratamiento por antimonio se ha descrito anteriormente, los fármacos derivados de este elemento químico, en nuestro medio el Glucantime ${ }^{\circledR}$, pueden inducir ataxia como parte de una lesión cerebral generalizada, puede atribuirse a su naturaleza como un medicamento que contiene metales pesados ${ }^{(4)}$.

Nuestro paciente recibió tratamiento para Leishmaniasis a los veinte años de edad, probablemente con algún antimonial, él y la familia no recuerdan el nombre del medicamento; en esta última infección recibió una dosis diaria Glucantime $^{\circledR}$ de tres ampolla diarias de $5 \mathrm{ml}$ que contiene 1.5 gr. del antimonial durante 17 días, debido a la mayor dosis administrada y al tiempo prolongado que recibió la medicación, tuvo más riesgo de presentar reacciones adversas. Hay que destacar que hasta antes de recibir este la medicación y a pesar de sus limitaciones cognitivas, tenía una vida independiente y podía vivir solo, sin ninguna asistencia. Los síntomas empezaron de 8 a 10 días después de haber recibido la última inyección. Al inicio no recibió atención médica, pero después que los síntomas le generan incapacidad ya que el temblor y las mioclonías se exacerbaban con la más mínima estimulación táctil, con imposibilidad de sostenerse en pie y menos iniciar la marcha, acudió al centro de salud de su comunidad. Otros reportes, han informado ataxia y temblor leves ${ }^{(3,9,10)}$; en nuestro paciente la clínica ha sido severa. También estos síntomas podrían estar en relación a que el paciente recibió asistencia médica tardía, después de veinte días. Las mioclonías generalizadas asociadas a antimoniales no han sido descritas previamente. La administración de corticoides no ayudó a mejorar los síntomas.

Los antimoniales pentavalentes siguen siendo las drogas de elección en casos de Leishmaniasis pero debido a su potencial riesgo de efectos adversos, dentro de los cuales se encuentran los movimientos anormales, deben administrarse con todas las precauciones necesarias, con una dosis exacta en relación al peso y durante los días indicados. Una vez iniciados los síntomas neurológicos, debe buscarse atención médica precoz si se retrasa la misma, puede provocar grave incapacidad, como en nuestro caso. Probablemente, la desaparición de las mioclonías y la ataxia será más exitosa si el inicio de tratamiento con Benzodiazepinas es más inmediato.

\section{Referencias bibliográficas}

1. Georgiadou S, Makaritsis K, Dalekos G. Leishmaniasis revisited: Current aspects on epidemiology, diagnosis and treatment. J Transl Int Med. 2015;3(2):43-50.

2. Frézard F, Demicheli C, Ribeiro R. Pentavalent Antimonials: New Perspectives for Old Drugs. Molecules 2009;14(7):23172336.

3. Oliveira L, Schubach A, Martins M, Passos S, Oliveira R, Marzochi M. Systematic review of the adverse effects of cutaneous leishmaniasis treatment in the New World. Acta Trop. 2011;118(2):87-96.

4. Khalil EA, Ahmed AE, Musa AM, Hussein MH. Antimonyinduced cerebellar ataxia. Saudi Med J 2006;27(1):90-92.

5. Del Rosal T, Baquero-Artiago F, García MJ. Leishmaniosis cutánea. Rev Pediatr Aten Primaria. 2010;12:263-271.

6. Burstein Z, Tejada A, Flores D, Fuchino H. Alternative theraphy for pure leishmaniasis. Traditional \& Kampo Medicine.2018;5(1):61-63.

7.David CV, Craft N. Cutaneous and mucocutaneous leishmaniasis. Dermatol Ther. 2009; 22(6): 491-502.

8. Chiragkumar JG, Jimishaben DK. Review on Leishmaniasis. Biomed J Sci \& Tech Res. 2017; 1(5):1-3.

9. Khalil EA, Ahmed AE, Musa AM, Hussein MH. Antimonyinduced cerebellar ataxia. Saudi Med J. 2006;27(1):90-92.

10.Sundar S, Chakravarty J. Antimony toxicity. Int J Environ Res Public Health. 2010;7(12):4267-4277.

Contribución de autoría: Torres-Ramírez Luis, Pérez-Almedo Melisa, Vélez-Rojas Miriam, Flores-Mendoza Martha, Arias-Hancco Víctor; han contribuido en el diseño, redacción, aprobación final del manuscrito y asumimos la responsabilidad frente a todos los aspectos del manuscrito.

Conflicto de interés: Los autores declaran no tener conflictos de interés en relación a los contenidos de este documento.

Financiamiento: Autofinanciado.

Citar como: Torres-Ramírez Luis, Pérez-Almedo Melissa, Vélez-Rojas Miriam, Flores-Mendoza Martha, Arias-Hancco Víctor. Temblor y mioclonías generalizadas provocadas por antimoniato de meglumina. Diagnóstico (Lima). 2020;59(1):35-37.

DOI: http://doi.org/10.33734/diagnostico.v59i1.207

Correspondencia: Luis Torres Ramírez. Correo electrónico: torresramirezl@hotmail.com 